\title{
Orijinal Çalışma
}

\section{Sağlık yüksekokulu öğrencilerinin evlilik dışı cinsel iliş̧i, istemli düşükler ve kontraseptif kullanımı konusundaki görüșleri}

\author{
Burcu Tokuça, Ufuk Berberoğlua, Gamze V. Saraçoğlub, Ülfiye Çelikkalpc
}

\begin{abstract}
Özet
Amaç: Bu çalışmanın amacı; sağlık yüksekokulu öğrencilerinin evlilik öncesi cinsel ilişki, istemli düşükler ve kontraseptif yöntem kullanımı konusunda görüşlerini belirlemek ve toplumsal değer yargılarını mesleki yaşantılarına yansıtmamaları konusunda farkındalık yaratmaktır. Yöntem: Kesitsel olarak planlanan araştırmaya, Mayıs-2008'de Trakya ve Namık Kemal Üniversitesi sağlık yüksek okullarında öğrenim gören toplam 338 ebelik ve hemşirelik öğrencisinin katılmıştır. Veriler araştırmacılar tarafından hazırlanan 25 maddelik bir soru formu ile toplanmıştır. Bulgular: Araştırmaya katılanların yaş ortalaması $20.9 \pm 1.6$ 'dır ve \%97'si kadındır. Öğrencilerin \%66.9'u "evlenmeden önce cinsel ilişkiye girmek yanlıştır"; \%63.6'sı "evlilik dışı ilişkiler bizim ahlaki ve kültürel değerlerimizi tahrip ediyor"; \%52.1'i "istemli düşük ahlaksal olarak yanlıştır"; yalnızca \%2.1'i ise "kontraseptif yöntemler ile ilgili bilgi yalnızca evli çiftlere verilmelidir" önermesine katıldıklarını belirtmişlerdir. Sonuç: Geleceğin sağlık çalışanları evlilik dışı cinsel ilişki, istemli düşükler ve kontraseptif kullanımı ile ilgili konularda toplumsal değer yargıları ve mesleki yaklaşımları arasında ikilem yaşamaktadırlar. Evlilik dışı cinsel ilişki ve istemli düşükler ahlaksal olarak yanlış bulunurken; planlanmamış bir gebelik durumunda istemli düşüğün kabul edilebileceğini ve evli olmayan genç kadınların istemli düşük hizmetlerinin, kürtajın fiziksel ve psikolojik sonuçlarını da kapsayacak şekilde verilmesi bu ikilemi açıkça göstermektedir. Sağlık alanında toplumsal değer yargılarının mesleki bağımsızlı̆̆ı ve tıbbi etik yaklaşımları etkilemesi olasılığını en aza indirmek amacıyla müfredat gözden geçirilmelidir.
\end{abstract}

Anahtar Kelimeler: Üreme sağlığı hizmetleri, evlilik öncesi cinsel ilişki, ergenler, mesleki tutum, kültürel değerler, ebelik ve hemşirelik eğitimi

\section{Opinions of health college students on premarital sex, induced abortions and contraceptive use of young people}

\begin{abstract}
Objective: The aim of the study was to investigate the health college students' opinions towards premarital sexual intercourse, induced abortion, and contraceptive use and to raise awareness about not to pass social and cultural values through to their professional life.

aYrd. Doç. Dr. Trakya Üniversitesi Tıp Fakültesi Halk Sağlığı Anabilim Dalı, Edirne

aYrd. Doç. Dr. Trakya Üniversitesi Tıp Fakültesi Halk Sağlı̆ı Anabilim Dalı, Edirne

bYrd. Doç. Dr. Namık Kemal Üniversitesi Tıp Fakültesi Halk Sağlığı Anabilim Dalı, Tekirdağ

cÖğr. Gör. Namık Kemal Üniversitesi Sağlık Yüksekokulu, Tekirdağ
\end{abstract}

Sorumlu Yazar: Burcu Tokuç, Trakya Üniversitesi Tıp Fakültesi Halk Sağlığı Anabilim Dalı, Edirne. Tlf: 0505 6177812, E-posta: burcutok@yahoo.com

Bu araştırma, 2009 Dünya Halk Sağlığı Kongresi'nde poster bildiri olarak sunulmuştur. 
Method: The cross-sectional study was conducted in Edirne and Tekirdağ health colleges with participation of 338 nursing and midwifery students, in May-2008. A 25 item questionnaire form prepared by researchers was used for collecting data. Results: The mean age of the participants is $20.9 \pm 1.6$ and $97 \%$ of them are women. Of the students, $66.9 \%$ expressed that "premarital sex is unacceptable in premarital period"; 63.6\% "fornication was battered our moral and cultural values"; $52.1 \%$ "curettage morally wrong" and only $2.1 \%$ of the students said they participated the "only married couples should be enlightened about contraceptive methods" proposition. Conclusion: Findings displayed a dilemma of the health professional of the future between society's condemnation and ethic rules of their profession about premarital sexual intercourse, induced abortions and contraceptive use of unmarried couples. Although most of the students believe premarital sexual intercourse and abortion morally wrong, they said adolescent abortion is acceptable in case of unplanned pregnancy and abortions services for unmarried young women should be comprised the physical and psychological consequences of induced abortions. Midwifery and nursing education should be considered in order to rule out the impact of the cultural values on professional independence and ethical approaches.

Key Words: Reproductive health services, premarital sexual intercourse, adolescents, professional attitude, cultural values, midwifery and nursing education

\section{Giriş}

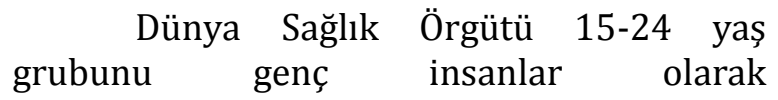
sınıflandırmaktadır. ${ }^{1}$ Gençlik dönemi genel olarak erişkin dönem yaşam tarzının belirlendiği özel bir dönemdir. $\mathrm{Bu}$ süreçte gençler birçok yeni norm, değer ve yaklaşımı benimseyerek bunları davranışlarına yansıtırlar. Gençler, cinsellik ve üreme davranışları ile ilgili norm ve değerlerini bu dönemde belirlerken pek çok bireysel ve toplumsal etmenden etkilenirler. ${ }^{1}$

Gençlerin üreme sağlığı ve cinsel sağlık sorunları gereksinimleri, sorun ve hakları özelikle son 25 yılda gündemdedir ve karşılan(a)mayan üreme sağlığ gereksinimleri dünyada ve ülkemizde önemli halk sağlı̆ı sorunları arasındadır. Karşılan(a)mayan üreme sağlı̆̆ gereksinimleri istenmeyen gebelikler, ergenlik dönemi gebelikleri, sağlıssız düşükler ve cinsel yolla bulaşan enfeksiyonlar ile sonuçlanmaktadır. ${ }^{2}$ Bir sorunu görmezlikten gelmek o sorunun olmadığ anlamına gelmemekte, gençler cinselliklerini yaşamakta ve istenmeyen gebelikler, cinsel yolla bulaşan enfeksiyonlar ile karşılaşmaktadırlar. Yaşanan bu sağlık sorunlarının bedeli kimi kez çok ağır ödenmektedir.
Cinselliğin evlilikle bağdaştırıldığı toplumlarda evlilik dişı cinsel ilişski; inkar, yasaklama ya da suskunlukla karşılanmakta ve bekar gençlerin üreme sağlığı hizmeti gereksinimi göz ardı edilmektedir. ${ }^{2}$ Sağlık çalışanlarının mesleki yaşantılarına toplumsal değer yargılarını yansıtmaları sunulan üreme sağlığı hizmetlerinin niteliğini ve kullanılabilirliğini olumsuz yönde etkileyebilmektedir. $\mathrm{Bu}$ sağlık çalışanları arasında en önemli grubu gençlerle ilk karşılaşan ebe ve hemşireler oluşturmaktadır. $\mathrm{Bu}$ yüzden, gençlere verilen cinsel sağlık ve üreme sağlığı hizmetlerinin niteliğini ve kullanılabilirliğini artırmak için, geleceğin sağlık çalışanları sağlık yüksekokulu öğrencilerinin evlilik dıșı cinsel ilişki, istemli düşükler ve kontraseptif kullanımı konusunda değer yargıları ve tutumlarını bilmek önemlidir.

$\mathrm{Bu}$ gerekçelerle çalışmamızın amacı; sağlık yüksekokulu öğrencilerinin evlilik öncesi cinsel ilişki, istemli düşükler ve evli olmayan çiftlerin kontraseptif yöntem kullanımı konusunda görüşlerini belirlemek ve toplumsal değer yargılarını mesleki yaşantılarına yansıtmamaları konusunda farkındalık yaratmaktır. 


\section{Yöntem}

Kesitsel tipte olan çalışma 2008 yılı Mayıs ayında gerçekleştirilmiştir. Araștırmanın evrenini Trakya Üniversitesi (Edirne) ve Namık Kemal Üniversitesi (Tekirdağ) sağlık yüksekokullarında okuyan toplam 471 öğrenci oluşturmuştur. Araştırmaya katılabilme ölçütleri sağlı yüksekokulu öğrencisi olmaktır. Yüksekokul öğrencilerinden 338'i araştırmaya katılmayı kabul etmiş ve araştırmaya katılım oranı \%71.7 olarak gerçekleşmiştir.

Araştırma verileri, araştırmacılar tarafından hazırlanmış 25 maddelik bir soru formu ile toplanmıştır. Soru formunun ilk altı sorusu öğrencilere ait temel demografik verileri ortaya koymak amaciyla hazırlanmıştır (cinsiyet, yaş, medeni durum, yaşanan yer). Kalan 19 soru ise daha önce yapılan kimi çalıșmalar doğrultusunda araştırmacılar tarafından üçlü Likert Tipi (katılıyorum, katılmıyorum, kararsızım) şeklinde hazırlanmıștır. Form evlilik dışı cinsel ilişki (11 soru), istemli düşükler (5) ve kontraseptif kullanımı (3) hakkında sağlık yüksekokulu öğrencilerin görüşlerini sorgulayan üç bölümden oluşmaktadır.

Araştırma için her iki Yüksekokul Müdürlükleri'nden gerekli izinler alınmış ve araştırma Trakya Üniversitesi Tıp Fakültesi Etik Kurulu tarafından onaylanmıștır. Tüm öğrenciler araştırma hakkında bilgilendirilmiş ve ögrenciler soru formunun ilk sayfasında araştırmaya katılma konusunda gönüllü imza ile beyan etmişlerdir. Araștırmaya katılan öğrencilere ödül, para, ek puan vb. gibi herhangi bir destek verilmemiştir. Çalışmaya katılmayı kabul eden öğrenciler, sınıf ortamında ve gözlem altında yaklaşık 10 dakikada soru formalarını doldurmuşlardır.

Tanımlayıcı istatistiksel analizler sonrasında, karşılaştırmalı istatistiksel analizlerde $\chi^{2}$ (ki-kare) analizi yapılmış ve sonuçlar \%95 güven aralığında çift yönlü olarak değerlendirilmiştir.

\section{Bulgular}

Çalışmaya katılan öğrencilerin 327'si (\%97) kadın, 11'i (\%3) erkektir ve yaș ortalaması 20.9 $\pm 1.6 \quad(18-27)$ 'dir. On iki öğrenci (\%3.6) evli, 324 öğrenci (\%95.9) bekardır. Öğrencilerin 78'i (\%23.1) ailesi ile birlikte, 73'ü (\%21.6) arkadaşları ile birlikte, 168'i (\%49.7) öğrenci yurdunda kalmaktadır. Öğrencilerin 142'si (\%42.0) yüksekokula bașlamadan önce il merkezinde, 138'i (\%40.8) ilçe merkezinde, 24'ü (\%7.1) beldede ve 25'i (\%7.4) köyde yaşadığını ifade etmiştir. Çalışmaya katılan öğrencilerin tamamının dini inancı İslam'dır.

Sağlık yüksekokulu öğrencilerinin evlilik dişı cinsel ilişki konusundaki görüşleri Tablo 1'de ayrıntılı olarak sunulmuştur. Öğrencilerin \%69.2'si bir kadının evlendiğinde bakire olması gerektiğine, \%66.9'u evlenmeden önce cinsel ilișkiye girmenin yanlış olduğuna, \%63.6'sı evlilik dışı ilişkilerin ahlaki ve kültürel değerlerimizi tahrip ettiği önermesine katıldıklarını belirtmiştir. Öğrencilerin \%49.7'si erkeğin kendisi ile evlenmeden cinsel ilișkiye giren bir kıza saygı göstermeyebileceği fikrine ve \%45.9'u evlilik öncesi seksten kaçınmanın ve bakire olmanın kişinin saygınlığını arttırdığına "katıldıklarını"; \%63.6'sı evlenmeyi düşündükleri bir kiși ile evlilik öncesi cinsel ilişkiye girme fikrini kabul etmediklerini belirtmiştir (Tablo 1).

Sosyo-demografik özelliklerine göre öğrencilerin evlilik dişı cinsel ilişki konusundaki görüşleri değerlendirildiğinde, "evlenmeyi planladığınız bir kişi ile evlilik öncesi cinsel ilişkiye girmek kabul edilebilir" $\left(p=0.01, \chi^{2}=8.9\right)$ ve "evlilik dışı cinsel ilişkinin sonuçlarına kadın tek başına katlanmalıdır" $\left(p=0.04, \quad \chi^{2}=6.2\right) \quad$ önermelerine verilen yanitlarda cinsiyete göre fark bulunmuştur. Erkekler daha yüksek sıklıkta birinci önermeye katıldıklarını, ikinci önermeye ise katılmadıklarını belirtmişlerdir. 
Tablo 1. Öğrencilerin evlilik dışı cinsel ilişkiye bakışları

\begin{tabular}{|c|c|c|c|c|}
\hline Önermeler & $\begin{array}{l}\text { Katılıyorum } \\
\text { n (\%) }\end{array}$ & $\begin{array}{l}\text { Katılmiyorum } \\
\text { n (\%) }\end{array}$ & $\begin{array}{c}\text { Kararsızım } \\
\text { n (\%) }\end{array}$ & $\begin{array}{c}\text { Yanitsız } \\
\text { n (\%) }\end{array}$ \\
\hline $\begin{array}{l}\text { Bir kadın için evlendiğinde bakire olması } \\
\text { önemlidir. }\end{array}$ & $324(69.2)$ & 72 (21.3) & $32(9.5)$ & - \\
\hline $\begin{array}{l}\text { Evlenmeden önce cinsel ilişkiye girmek } \\
\text { yanlıştır }\end{array}$ & 226 (66.9) & $79(23.4)$ & $30(8.9)$ & $3(0.9)$ \\
\hline $\begin{array}{l}\text { Erkekler evlenmeden önce cinsel iliş̧kiye } \\
\text { girebilir. }\end{array}$ & $82(24.3)$ & 189 (55.9) & 63 (18.6) & $4(1.2)$ \\
\hline $\begin{array}{l}\text { Evlenmeyi planladı̆̆ınız bir kişi ile evlilik } \\
\text { öncesi cinsel iliş̧kiye girmek kabul } \\
\text { edilebilir. }\end{array}$ & $60(17.8)$ & 215 (63.6) & $58(17.2)$ & $5(1.5)$ \\
\hline $\begin{array}{l}\text { Bir erkek kendisi ile evlenmeden cinsel } \\
\text { ilişkiye giren bir kıza saygı göstermeyebilir. }\end{array}$ & 168 (49.7) & $113(33.4)$ & $92(15.4)$ & $5(1.5)$ \\
\hline $\begin{array}{l}\text { Kızlar evlilik öncesi cinsel ilişkiye girerse } \\
\text { cezasını çekmelidir. }\end{array}$ & 24 (7.1) & $270(75.9)$ & $42(12.4)$ & $2(0.6)$ \\
\hline $\begin{array}{l}\text { Evlilik dışı cinsel ilișkinin sonuçlarına } \\
\text { kadın yalnız başına katlanmalıdır. }\end{array}$ & $14(4.1)$ & 309 (91.4) & $15(4.4)$ & - \\
\hline $\begin{array}{l}\text { Evlilik öncesi seksten kaçınmak ve bakire } \\
\text { olmak kişinin saygınlığını arttırır }\end{array}$ & 155 (45.9) & $130(38.5)$ & $52(15.4)$ & $1(0.3)$ \\
\hline $\begin{array}{l}\text { Evlilik öncesi seksten kaçınmak ve bakire } \\
\text { olmak sağlıklı bir yaşam biçimidir. }\end{array}$ & $194(57.4)$ & 83 (24.6) & $59(17.5)$ & $2(0.6)$ \\
\hline $\begin{array}{l}\text { Evlilik dışı kurulan cinsel ilişkide kadın ve } \\
\text { erkeğin sorumlulukları eşittir. }\end{array}$ & 309 (91.4) & $14(4.1)$ & $13(3.8)$ & $2(0.6)$ \\
\hline $\begin{array}{l}\text { Evlilik dışı ilişkiler bizim ahlaki ve kültürel } \\
\text { değerlerimizi tahrip ediyor. }\end{array}$ & $215(63.6)$ & $58(17.2)$ & $63(18.6)$ & $2(0.6)$ \\
\hline
\end{tabular}

Araştırmaya katılan sağlık yüksekokulu öğrencilerinin istemli düşükler konusundaki görüşleri Tablo 2'de verilmiştir. Öğrencilerin \%52.1'i istemli düşüğün ahlaksal olarak yanlış olduğuna "katıldıklarını" belirtmişlerdir. "Planlanmamış bir gebelik durumunda, adölesan kizların kürtaj yaptırması kabul edilebilir" önermesine ise yalnızca \%37.9'u katılmış, \%25.7'si kararsız kalmıştır (Tablo 2).
Öğrencilerin sosyo-demografik özelliklerine göre istemli düşükler konusundaki görüşleri arasında fark yoktur.

Sağlık yüksekokulu öğrencilerinin kontraseptif yöntem kullanımı ile ilgili görüşleri Tablo 3'te sunulmuştur. Öğrencilerin büyük çoğunluğu "kontraseptif yöntemler ile ilgili bilgi yalnızca evli çiftlere verilmelidir" (\%95.6) ve "doğum kontrol yöntemleri ile ilgili danışmanlık almak isteyen bekar kızlar, kötü kızlardır" (\%96.2) önermelerine katılmadıklarını belirtmiştir. 
Tablo 2. Öğrencilerin istemli düşük (kürtaj) konusundaki görüşleri

\begin{tabular}{|c|c|c|c|c|}
\hline Önermeler & $\begin{array}{c}\text { Katılıyorum } \\
\text { n (\%) }\end{array}$ & $\begin{array}{l}\text { Katılmıyorum } \\
\text { n (\%) }\end{array}$ & $\begin{array}{c}\text { Kararsızım } \\
\text { n (\%) }\end{array}$ & $\begin{array}{c}\text { Yanitsız } \\
\text { n (\%) }\end{array}$ \\
\hline $\begin{array}{l}\text { Türkiye'de evlenmemiş genç kadınlarda } \\
\text { istemli düşük (kürtaj) oranı artmaktadır. }\end{array}$ & 283 (83.7) & $12(3.6)$ & $42(12.4)$ & $1(0.3)$ \\
\hline $\begin{array}{l}\text { İstemli düşük (kürtaj) ahlaksal olarak } \\
\text { yanlıştır. }\end{array}$ & $176(52.1)$ & 97 (28.7) & $56(16.6)$ & $9(2.7)$ \\
\hline $\begin{array}{l}\text { Planlanmamış bir gebelik durumunda, } \\
\text { adölesan kızların kürtaj yaptırması kabul } \\
\text { edilebilir. }\end{array}$ & $128(37.9)$ & $120(35.5)$ & 87 (25.7) & $3(0.9)$ \\
\hline $\begin{array}{l}\text { Evlilik öncesi cinsel ilişki olmaması } \\
\text { evlenmemiş genç kadınlarda kürtaj } \\
\text { sayısını azaltmak için en iyi çözümdür. }\end{array}$ & $165(48.8)$ & 99 (29.3) & 67 (19.8) & $7(2.1)$ \\
\hline $\begin{array}{l}\text { Evli olmayan genç kadınlar için istemli } \\
\text { düşük (kürtaj) hizmetleri, kürtajın fiziksel } \\
\text { ve psikolojik sonuçlarını da kapsayacak } \\
\text { şekilde verilmelidir. }\end{array}$ & $305(90.2)$ & $16(4.7)$ & $12(3.6)$ & $5(1.5)$ \\
\hline
\end{tabular}

Öğrencilerin sosyo-demografik özelliklerine göre kontraseptif kullanımı konusundaki görüşleri arasında "doğum kontrol yöntemleri ile ilgili danışmanlık almak isteyen evlenmemiş çiftler sorumluluk örneği göstermektedirler" önermesine verilen yanıtlarda cinsiyete göre fark bulunmuştur $\left(p=0.02, \chi^{2}=7.4\right)$. Erkekler daha yüksek oranda katıldıklarını belirtmişlerdir.

\section{Tartışma}

Sunulan çalışmada toplumumuzun geneli tarafından önemli ahlaki konular arasında yer alan evlilik dişı cinsel ilişki, istemli düşük ve kontraseptif yöntem kullanımı gibi konular ele alınmıştır. Çalışmada, gelecekte sağlık çalışanları olarak görev yapacak olan sağlık yüksekokulu öğrencilerinin toplumun bir parçası olarak bahsedilen konularda benzer yaklaşımları olduğu belirlenmiştir. Çalışmamızda evlilik dışı ilişkilerin kültürel değerleri tahrip ettiği görüşüne öğrencilerin \%63.6'sı katılırken; üniversite öğrencilerinde yapılan bir çalışmada öğrencilerin yaklaşık yarısının evlilik öncesi cinsel ilişkinin sosyal düzeni bozduğunu belirlenmiştir. ${ }^{3}$ Çalışmamızda evlilik dıșı ilişkinin yanlış olduğunu düşünenlerin sıklığı \%66.9'dur. Erbil ve Top'un çalışmasında da çalışmamıza benzer olarak üniversite öğrencilerinin \%69'u evlilik öncesi cinsel ilişkiye karşı olduklarını belirtmişlerdir. ${ }^{4}$ Sonuçların benzerliğinden yola çıkarak sağlık yüksekokulu öğrencilerinin aldıkları mesleki eğitimden bağımsız olarak içinde yaşadıkları toplumla ortak kültürel değerleri taşıdıkları söylenebilir. Buna karşın çoğu bekar olan sağlık yüksekokulu öğrencilerinin (\%95.9) kontraseptif kullanımı ve istemli düșükler konusunda katıldıklarını belirttikleri görüşler aldıkları eğitimin etkisini de yansıtmaktadır.

Öğrencilerin 2/3'ü evlilik dışı cinsel ilişkiyi yanlış bulsa da, daha az bir sıklıkla evlilik öncesi seksten kaçınmanın ve bakire olmanın sağlıklı bir yaşam biçimi olduğu (\%57) ve kişinin saygınlığını artırdığını 
(\%46) söylemiştir. Ancak, toplum tarafından dışlanma, kötü gözle bakılma, taciz edilme gibi yollarla cezalandırılan evlilik dışı cinsel ilişkiye girmiş kadınlara öğrencilerin büyük çoğunluğu (\%90.2) sorumlu bir sağlık çalışanı yaklaşımı ile "evli olmayan genç kadınlar için istemli düşük hizmetleri, kürtajın fiziksel ve psikolojik sonuçlarını da kapsayacak şekilde verilmelidir" önermesine katıldıklarını belirtmişlerdir. Birçok uluslararası çalışma, bizim çalışmamızdaki öğrencilerde olduğu gibi, üreme sağlığı hizmetlerinde çalışan ebe ve hemşirelerin toplumsal ve mesleki değerler arasında sıkça ikilem yaşadığını ortaya koymuştur.5,6

Tablo 3. Öğrencilerin evli olmayanların kontraseptif kullanımı ile ilgili görüşleri

\begin{tabular}{lcccc}
\hline Önermeler & $\begin{array}{c}\text { Katılıyorum } \\
\mathbf{n}(\%)\end{array}$ & $\begin{array}{c}\text { Katılmıyorum } \\
\mathbf{n}(\%)\end{array}$ & $\begin{array}{c}\text { Kararsızım } \\
\mathbf{n}(\%)\end{array}$ & $\begin{array}{c}\text { Yanıtsız } \\
\mathbf{n}(\%)\end{array}$ \\
\hline $\begin{array}{l}\text { Doğum kontrol yöntemleri ile ilgili bilgi } \\
\text { yalnızca evli çiftlere verilmelidir. }\end{array}$ & $7(2.1)$ & $323(95.6)$ & $6(1.8)$ & $2(0.6)$ \\
$\begin{array}{l}\text { Doğum kontrol yöntemleri ile ilgili } \\
\text { danışmanlık almak isteyen bekâr kızlar, } \\
\text { kötü kızlardır. }\end{array}$ & $6(1.8)$ & $325(96.2)$ & $5(1.5)$ & $2(0.6)$ \\
$\begin{array}{l}\text { Doğum kontrol yöntemleri ile ilgili } \\
\text { danışmanlık almak isteyen evlenmemiş } \\
\text { çiftler sorumluluk örneği } \\
\text { göstermektedirler }\end{array}$ & $271(80.2)$ & $29(8.6)$ & $35(10.4)$ & $3(0.9)$ \\
\hline
\end{tabular}

$\mathrm{Bu}$ çalıșmada öğrencilerin sahip olduğu benzer bir ikili bakış açısı, istemli düşükler için de söylenebilir. Öğrencilerin yarısı toplumsal değer yargılarına paralel olan "istemli düşük ahlaksal olarak yanlıştır" görüşüne katılsa da; \%38'i meslek etiğine uygun olarak, "planlanmamış bir gebelik durumunda genç kızların kürtaj yaptırması kabul edilebilir" görüşüne katıldığını, \%26’sı da bu konuda kararsız olduğunu bildirmişlerdir. Konya'da ebelik öğrencilerinde yapılan bir çalışmada da bulgularımıza benzer olarak öğrencilerin \%51'i kürtajı ahlaki olarak yanlış bulmuş; \%38'i istemediği bir gebeliği sürdürmenin bir genç kız için kabul edilemez olduğu görüşüne katılmıştır. ${ }^{7}$ Bulgular toplumun içinden çıkan sağlık çalışanlarının meslek uygulamaları sırasında toplumsal değer yargılarını yansıtmamaya çalıştıklarını göstermektedir.
Toplumların kültürü, gelenekleri, dini yapısı vb kimi özellikleriyle şekillenen 'toplumsal cinsiyet' olgusuna baktığımızda, her toplumda farklı boyutlarda olmak üzere kadınların cinselliğinin denetlendiği görülmektedir. ${ }^{8}$ Buna paralel olarak kadınların evlilik dıșı ilișki kurmaları da toplumsal olarak 'kabul edilemez' bir durumdur. Böyle bir toplumsal cinsiyet ortamı, evlilik dışı cinsel ilişki kuran genç bir kadının sağlık hizmetine erișiminin önünde önemli bir bariyerdir. Buna ek olarak sağlık çalışanlarının toplumun hakim kültürel ve ahlaki değerlerini mesleki uygulamalarına yansıtmaları, sağlık hizmeti almaya gelenlerin sağlık hakkını kullanmalarını engelleyebilir. Diğer yandan neredeyse tamamının (\%97) kadın olduğu araştırma katılımcılarının genç kızlar için biçilmiş toplumsal cinsiyet rolünü içselleştirmiş oldukları da ortaya çıkmaktadır. 
Sunulan çalışmada da geleceğin ebehemşireleri olacak sağlık yüksekokulu öğrencilerinin, gençlerin evlilik dışı cinsel ilişki kurması, istemli düşükler ve kontraseptif yöntem kullanımı gibi hassas konularda meslek etiği kurallarını dikkate alan yaklaşımlarının toplumsal ahlaki değer yargılarından etkilendiği söylenebilir. Değerlendirmemizi destekleyen bir çalışma da Vietnam'da yapılmıştır; düşük kliniklerinde çalışan ve sağlık hizmeti sunan sağlık çalışanlarında ergenlerde evlilik dışı cinsel ilişkiyi ve kürtajı onaylamasa da, kürtaj için gelen genç hastalarına hizmet verdiklerini söylemişlerdir. 9 Temel yaklaşım mesleki uygulamaların toplumsal değer yargılarından etkilenmesini engelleyecek mekanizmalar üretilmesi șeklinde olmalıdır.

Ülkemizde toplumsal cinsiyet eşitliği konusunda ikiyüzlü bir ahlak anlayışı vardır. Araştırmacılar gelecekte üreme sağlığı hizmetlerini de sunacak olan sağlı yüksekokulu öğrencilerinin toplumun cinsiyet eșitliği konusundaki yaklașımlarına daha fazla tepki göstereceğini beklerken; araştırmaya katılan öğrencilerin \%24'ü "erkekler evlenmeden önce cinsel ilișkiye girebilir" önermesine katıldığını, \%19'u da bu konuda "kararsız" kaldığını belirtmiştir. Ama aynı öğrencilerin \%91'i "evlilik dişı cinsel ilişkinin sonuçlarına kadın yalnız başına katlanmalıdır" önermesine ve \%96'sı da "doğum kontrol yöntemleri ile ilgili bilgi almak isteyen bekar kızlar, kötü kızlardır" önermesine katılmadıklarını belirtmişlerdir. Ülkemizle cinsiyet ve evlilik dişı cinsel ilişkiye toplumsal bakıșı benzer olan Vietnam'da, yapılan bir çalışmada öğrencilerin tamamına yakını erkeklerin de evlilik dışı cinsel ilişkiye girmesini yanlış bulmuştur. 10 Ülkemizde halen evlilik öncesi cinsel ilişki deneyimi erkekler için toplumsal onay görürken, kızlar için töre cinayetlerine varan bir toplumsal tepkiye neden olabildiği göz önüne alındığında öğrencilerin böyle bir ikilem içinde olmaları doğal görünmektedir. "Evlenmeyi planladığınız bir kişi ile evlilik öncesi cinsel ilişkiye girmek kabul edilebilir" ve "evlilik dışı cinsel ilişkinin sonuçlarına kadın tek başına katlanmalıdır", "doğum kontrol yöntemleri ile ilgili danışmanlık almak isteyen evlenmemiş çiftler sorumluluk örneği göstermektedirler" önermelerine verilen yanıtlarda cinsiyete göre fark bulunması ve erkek öğrencilerin sürece daha açık fikirli bakmaları tam da toplumsal cinsiyet kalıplarına uygun elde edilmiş sonuçlardır. Türkiye gibi nüfusun çoğunun Müslüman ve cinselliğin tabu olduğu ülkelerde erkekler daha özgür yaşamakta, üzerlerinde daha az toplumsal baskı hissetmektedirler. Kı öğrenciler ise toplumun kendilerine biçtikleri toplumsal cinsiyet rollerinden daha derinden etkilenmekte, yaşadıkları çevre, toplumsal/kültürel baskı kendi kendilerini sinırlandırmalarına yol açmaktadır. Bulgularımız kız öğrencilerin, bahsedilen konularda erkek öğrencilere kıyasla değer yargıları ile mesleki etik değerleri arasındaki daha derin bir ikilem yaşayabileceği şeklinde yorumlanabilir. $\mathrm{Bu}$ iki ayrı bakış açısı Vietnam'da yapılan çalışmada olduğu gibi "toplumsal değer yargıları" ve "sağlık bakımı etiği" olarak kavramlaştırılabilir. ${ }^{10}$ Botes'in de önerdiği gibi sağlık hizmeti sunanlar, sağlık bakımı verirken adil ve tarafsız olmak için, kararlarında hem toplumsal değer yargıları hem de sağlık hizmeti açısından bakmak zorundadırlar. ${ }^{11} \mathrm{Bu}$ iki bakış açısını "toplumsal değerler" ve "bakım etiği" olarak adlandırmak, birinin diğerinden daha insancıl ya da uygun olduğu şeklinde anlaşılmamalı dahası, bunlar toplumlardaki ahlaki nedensellik eğilimlerini kavramsallaştırmak için kullanılmalıdır. ${ }^{3}$

Sonuç olarak; gençlere üreme sağlığı ve cinsel sağlık hizmetlerini de verecek olan ebe ve hemşireler toplumun katı ahlaki değerleri ve günümüzde hızla değișen gençlik kültürünün cinsel ilișki ve evlilik anlayıșı arasında kritik bir noktada bulunmaktadır. $\mathrm{Bu}$ durum sağlık çalışanlarının da toplumsal değer yargıları ile mesleki sorumlulukları arasında farkında olmadan ikilem yaşamalarına neden olabilir. Sağlık alanında öğrenim gören ya da çalışan profesyonellere mezuniyet öncesi ve sonrası eğitimlerle 
yaşanması olası etik ikilemler ve korunmasız cinsel ilişkilerin yol açacağı istenmeyen sonuçlara dair bilgilendirmelere daha fazla yer verilmelidir. Öğrenciler doğru kararlar verme, değer yargllarından uzaklaşıp profesyonelce davranma ve gerektiğinde destek alabilme konusunda güçlendirilmelidir. Tüm bunlar ebe ve hemşirelerin üreme sağlı̆̆ hizmeti için başvuran gençlerle iletişimini kolaylaştıracak

\section{Kaynaklar}

1. UNFPA, Nüfusbilim Derneği. Türkiye Gençlerde Cinsel Sağlık Ve Üreme Sağlığı Araştırması Raporu. Ankara: Damla Yayıncılık; 2007. s.5.

2. Giray H, Kılıç B. Bekar kadınlar ve üreme sağlığl. STED 2004; 13(8): 286-9.

3. Kadıŏlu H. Yıldız A, Ercan N, Ergun A. Üniversite öğrencilerinin cinsellik ve cinsel eğitim ile ilgili görüşleri. STED 2008; 17(3): 32-7.

4. Erbil N, Top F. Üniversite öğrencilerinin cinsellik bilgi, tutum ve davranışları. 4. Uluslararası Üreme Sağlığı ve Aile Planlaması Kongresi Kitabı, Ankara, 2005 s. 220-1.

5. Berggren V, Salam GA, Bergstöm S, Johanson E, Edberg A. An explorative study of Sudanese midwives motives, perceptions and experiences of reinfibulation after birth. Midwifery 2004; 20: $299-311$.

6. Cook RJ, Dickens BM, Fathalla MF. Female genital cutting: ethical and legal dimensions. International J Gyneocology and Obstetrics 2002; 79: 281-7. ve hızla değişen toplumlarda karmaşık gerçeklerle daha kolay başa çıkmalarını sağlayacaktır.

Temel önerimiz sağlık alanında toplumsal değer yargilarının, mesleki bağımsızlığı ve tıbbi etik yaklaşımları etkilemesi olasılığını en aza indirmek amacıyla müfredat yenilenmeli ve hizmet içi eğitimlerin düzenlenmesidir.

7. Ege E, Akın B, Altuntuğ K. Opinions of midwifery students on adolescents sexuality and reproductive health in Turkey. Social Behavior and Personality 2008; 36(7): 965-72.

8. Acar-Savran G. Beden Emek Tarih. İstanbul. Kanat Kitap. 2004.

9. Klingberg-Allvin M, Nga NT, RansjöArvidson AB, Johansson A. Midwives and doctors perspective on adolescent abortion care and contraceptive counseling in Vietnam. Scand J Public Health 2006; 34(4): 414-21.

10. Klingberg-Allvin $M$, Tam VV, Nga NT, Ransjo-Arvidson $\mathrm{AB}$, Johannson $\mathrm{A}$. Ethics of justice and ethics of care, values and attitudes among midwifery students on adolescent sexuality and abortion in Vietnam and their implications for midwifery education: A survey by questionnaire and interview. International J Nursing Studies 2007; 44: 37-46.

11. Botes A. A comparison between the ethics of justice and the ethics of care. Journal of Advanced Nursing 2000; 32(5): 1071-5. 